Байкальский государственный университет, г. Иркутск, Российская Федерация

О. Ю. Оношко

Байкальский государственный университет, 2. Иркутск, Российская Федерация

\title{
РОЛЬ ЭФФЕКТИВНОГО КОРПОРАТИВНОГО УПРАВЛЕНИЯ В СИСТЕМЕ МИНИМИЗАЦИИ РИСКОВ КОММЕРЧЕСКОГО БАНКА
}

\begin{abstract}
АНнОтАЦИЯ. В настоящее время корпоративное управление становится все более значимым фактором, обеспечивающим управление рисками коммерческого на необходимом для безопасного функционирования банковской системе уровне. Анализ российской и зарубежной экономической литературы позволяет рассмотреть эволюцию в рассматриваемых подходах, выявить основные различию и схожие черты. В статье рассматривается роль корпоративного управления в системе минимизации рисков коммерческого банка, рассматриваются традиционные концепции и принципы корпоративного управления, описанные в зарубежной литературе. Описываются основные элементы, присущие той или иной модели корпоративного управления. Проводится анализ, причин наибольшей значимости корпоративного управления для банковской системы в отличие от любых других экономических элементов. Рассматривается причина возрастании роли корпоративного управления в периоды экономических кризисов. В статье находит подтверждение гипотеза о взаимосвязи грамотного корпоративного управления с экономической безопасностью субъекта, особенно в периоды проявления кризисных явлений в экономике и обобщаются имеющиеся научные подходы к вопросу о роли корпоративного управления в системе минимизации рисков коммерческого банка.

кЛЮчЕВЫЕ СлОВА. Структура управления; корпоративное управление; коммерческий банк; минимизация рисков; риск-менеджмент.

ИНФОРМАЦИЯ О СТАТЬЕ. Дата поступления 22 апреля 2017 г.; дата принятия к печати 4 мая 2017 г.; дата онлайн-размещения 19 июня 2017 г.
\end{abstract}

Ye. I. Golovan

Baikal State University, Irkutsk, Russian Federation

O. Yu. Onoshko

Baikal State University,

Irkutsk, Russian Federation

\section{ROLE OF EFFECTIVE CORPORATE MANAGEMENT IN THE COMMERCIAL BANK'S SYSTEM OF RISK MINIMIZATION}

ABSTRACT. At present, corporate management is becoming an increasingly important factor that ensures management of commercial risks at the level necessary for safe operation of the banking system. Analysis of Russian and foreign economic literature allows to examine evolution in the approaches under consideration, to identify the main differences and similarities. The article examines the role of corporate management in the system of minimizing risks of the commercial bank, considers traditional concepts and principles of corporate management described in foreign literature. It describes basic elements inherent in this or that model of corporate management. It carries out an analysis of the reasons for the greatest importance of corporate management for the banking system, unlike any other economic elements. The article examines the reason for the increase in the corporate management role during periods of economic crises. It confirms the hypothesis about the interrelation

(C) Е. И. Головань, О. Ю. Оношко, 2017

\section{Baikal Research Journal}


between competent corporate management and the economic security of the subject, especially during periods of crisis phenomena in the economy and summarizes the available scientific approaches to the issue of the corporate management role in the system of minimizing the risks of the commercial bank.

KEYWORDS. Management structure; corporate management; commercial bank; minimization of risks; risk management.

ARTICLE INFO. Received April 22, 2017; accepted May 4, 2017; available online June 19, 2017.

Исследование роли эффективного корпоративного управления, как одной из составляющих систем минимизации рисков коммерческого банка, становится все более актуальной темой, особенно в период проявления кризисных явлений в экономике, что делает данную тематику высоко социально значимой в данный период времени.

В то же время, занимаясь исследованием проблем корпоративного управления и риск-менеджмента применительно к банковской сфере, необходимо учитывать специфичность банковской деятельности, что может приводить к эффекту мультиплицирования негативных последствий от принятия неверных управленческих решений для системы минимизации рисков. В чем же именно заключается принципиальное отличие банковской сферы от любой другой, что увеличивает роль эффективного корпоративного управления в системе минимизации рисков?

Одним из принципиальных отличий, встречающимся в многочисленных источниках литературы, является особенность поддержания ликвидности банка по сравнению с коммерческими организациями нефинансового сектора, основанная на несоответствии структуры сроков активов и обязательств банка. Как следствие, существование банков в решающей степени зависит от непрерывного доступа к ликвидности, будь то депозиты, краткосрочное финансирование на межбанковском рынке или финансирование из Центрального банка в качестве источника ликвидности, в крайнем случае [1, с. 10].

Вторым важным отличием является высокая социальная значимость банковской сферы. Посредством банковского сектора происходит аккумулирование одних финансовых ресурсов в виде вкладов и депозитов от физических и юридических лиц и их перераспределение в другие отрасли экономики, различным слоям и группам населения в виде кредитов. Также посредством банковского сектора происходит стимулирование экономики за счет предоставления во временное пользование финансовых ресурсов нуждающимся в оборотных средствах малым, средним и крупным предприятиям. Посредством принятия денежных средств населения во вклады и гарантируя их сохранность, банковский сектор помогает государству реализовывать свои социальные функции.

Логичным продолжением предыдущих пунктов является еще одно отличие высокая (для российской практики - преобладающая) доля кредитных операций в структуре активов банка, что значительно увеличивает риски и требует более грамотного корпоративного управления в области сбалансированности активов. Следовательно, при прочих равных условиях, прибыль банка увеличивается непосредственно пропорционально объему кредитования. Верхняя граница увеличения объема кредитования основана на предельных издержках рефинансирования банка, учитывая, что увеличение кредитного плеча банка повысит его вероятность дефолта, а вкладчики, а также другие дебиторы будут требовать более высокую премию за риск в качестве компенсации. Говоря об организациях нефинансового сектора, политика в области минимизация кредитного риска, который может возникать, к примеру, при предоставлении отсрочки платежей или оплаты поставок

\section{Baikal Research Journal}

электронный научный журнал Байкальского государственного университета 
после получения товара при торговых операциях, является одним из основополагающих моментов при обеспечении экономической безопасности экономического субъекта. В противоположность этому, кредитование в банковской сфере является обычной деятельностью, следовательно, корпоративное управление в системе минимизации рисков начинает играть более значимую роль.

Таким образом, суммируя наиболее значимые для роли корпоративного управления отличия банков и нефинансовых организаций, можно привести еще одно глобальное отличие - из-за их системного значения, с одной стороны, и их уязвимости, с другой стороны, банки являются сильно регулируемыми и контролируемыми организациями [2].

В основном банковское регулирование ограничивает объем риска, который банк может принять, в частности, в соответствии с компонентом пересмотренной структуры Базельского комитета по банковскому надзору (Базель III). Концепция функционирует:

- лимитируя величину риска по одному заемщику или группе заемщиков;

- устраняя риск перебоев в доступе к достаточной ликвидности путем установления стандартов управления ликвидностью;

- устанавливая риск корректировки минимальных требований к капиталу, то есть путем увязки необходимого нормативного регулирования капитала и активов банка (кредиты, ценные бумаги и другие активы) в довольно сложном подходе к скорректированному весу риска различных активов.

В то же время в литературе встречается мнение, что на еще более фундаментальном уровне это может создать дополнительные стимулы для банков замещать менее рискованные активы более рисковыми активами с более высокой доходностью, чтобы компенсировать «потери» из-за ограничений бизнеса, налагаемых потолком плеча. Следовательно, коэффициент левериджа должен быть подкреплен дополнительными гарантиями, скорректированными с учетом риска, что, в свою очередь, может вызвать сомнения в эффективности всей концепции [1, с. 13$]$.

Выделенные различия отражены как в практике корпоративного управления, наблюдаемой в банковском секторе, так и в теоретических работах по эффективному корпоративному управлению банками. Для того чтобы разобраться, насколько значительную роль играет эффективное корпоративное управление для минимизации рисков в коммерческом банке, необходимо уточнить само понятие корпоративного управления применительно к банковскому сектору в зарубежной и российской практике.

Традиционные концепции в зарубежной литературе описывают корпоративное управление как механизм, который осуществляет контроль над принятием решений внутри фирмы. Иначе говоря, корпоративное управление имеет дело с принятием решений на уровне совета директоров и высшего руководства (т. е. правления в двухуровневой системе), а также различных внутренних и внешних механизмов, которые гарантируют, что все решения, принимаемые директорами и топ-менеджментом соответствует целям компании и ее акционеров, соответственно [3].

Принципы корпоративного управления ОЭСР, в частности, упомянутые в Плане действий Комиссии ЕC по вопросам корпоративного права и корпоративного управления, несколько шире: «Корпоративное управление включает в себя набор взаимоотношений между руководством компании, ее советом, акционерами и другими заинтересованными сторонами» ${ }^{1}$.

Корпоративное управление также обеспечивает структуру, с помощью которой устанавливаются цели компании, а также определяются способы достижения

${ }^{1}$ Principles of Corporate Governance (Paris: OECD, 2004). URL: www.oecd.org/daf/corporateaffairs/ principles/text.

\section{Baikal Research Journal}


этих целей и мониторинга эффективности. Эффективное корпоративное управление должно обеспечивать надлежащие стимулы для совета директоров и руководства для достижения целей, которые отвечают интересам компании и ее акционеров, и должны способствовать эффективному мониторингу [1, с 4]. Это определение выходит за рамки приведенных выше определений, главным образом в том, что касается цели компании, а механизм постановки цели (целей) рассматривается как проблема корпоративного управления, а не как закономерная данность. Корпоративное управление «рассматривает способы, с помощью которых собственники финансов для корпораций гарантируют себе получение прибыли от своих инвестиций» [Там же, с. 737].

В отличие от этого, более широкое определение описывает корпоративное управление как «стандарты для принятия решений в рамках компании, обязанностей членов совета директоров и должностных лиц, внутренней структуры фирмы (предприятия) и взаимоотношений между корпорацией, ее акционерами и другими заинтересованными сторонами. Такая концепция корпоративного управления выходит за рамки даже определения ОЭСР в двух отношениях: Во-первых, подразумевая, что корпоративное управление также занимается вопросами материального управления, а во-вторых, касается внутренней структуры фирмы, то есть внутренней структуры ниже уровня правления и должностных лиц компании (высшее руководство) [Там же, с. 4-5].

Эта гораздо более широкая концепция в значительной степени согласуется с пониманием органами банковского надзора корпоративного управления, изложенными в руководстве Базельского комитета по банковскому надзору, озаглавленном «Повышение эффективности корпоративного управления для банковских организаций». В руководстве указывается, что «с точки зрения банковской отрасли корпоративное управление включает в себя то, как бизнес и деятельность банков управляются советом директоров и высшим руководством, которое, в частности, влияет на то, как они [Там же]:

- устанавливают корпоративные цели;

- управляют бизнесом банка ежедневно;

- выполняют обязанности подотчетности перед своими акционерами и учитывают интересы других признанных заинтересованных сторон (в том числе, среди прочего, надзорных органов, правительств и вкладчиков);

- выстраивают деятельность с учетом необходимости действовать безопасно и рационально и в соответствии с применимыми законами и правилами;

- защищают интересы вкладчиков.

В российской практике также существует множество определений понятия «корпоративное управление». Одни исследователи при рассмотрении содержания корпоративного управления чаще всего делают акцент на отдельных наиболее характерных чертах, присущих той или иной модели корпоративного управления. Другие связывают понятие корпоративного управления с применением его только в акционерных структурах, где четко просматривается разделение интересов собственников и функций менеджмента. В определениях корпоративного управления большинства авторов отсутствуют многие моменты, характеризующие существенные стороны корпоративного управление, либо в них не указывается цель корпоративного управления. При всем этом в большинстве определений корпоративного управления имеется и ряд общих элементов, характеристик и подходов, а именно [5]:

- корпоративное управление - это система взаимоотношений, характеризуемая определенными структурами и процессами;

- отдельные участники корпоративных взаимоотношений имеют различные (иногда даже противоположные) интересы;

\section{Baikal Research Journal}


- все стороны системы корпоративного управления должны иметь возможность участвовать в управлении компанией и осуществлении контроля за ее деятельностью;

- система корпоративных отношений должна быть направлена на обеспечение справедливого распределения прав и обязанностей всех субъектов, имеющих отношение $\kappa$ ней.

По мнению Е. А. Федоровой, организация и координация управления банковскими рисками в любом коммерческом банке предусматривает [6]:

- участие в системе управления банковскими рисками совет директоров, единоличного и коллегиального исполнительного органа банка;

- систему сбора, обработки и доведения до органов управления соответствующих информации обо всех значимых для банка банковских рисках;

- создание структурных подразделений, ответственных за координацию управления всеми банковскими рисками банка.

Процесс управления рисками с позиции корпоративного управления коммерческим банком может быть, по мнению Е. А. Федоровой, реализован в виде алгоритма [Там же]:

- утверждает предельно допустимый совокупный уровень риска по банку и периодичность его пересмотра;

- утверждает политику ограничения банковских рисков по всем банковским операциям и другим сделкам, проводимым банком, а также осуществления контроля за разработкой исполнительными органами правил и процедур, необходимых для соблюдения этой политики;

- периодически рассматривает размер внутрибанковских лимитов на предмет их соответствия изменениям в стратегии развития, особенностям предоставляемых банком новых банковских услуг, общему состоянию рынка финансовых услуг;

Утверждает перечень банковских операций и других сделок, для осуществления которых необходимо производить оценку качества корпоративного управления юридического лица, являющегося контрагентом.

Члены совета директоров и исполнительных органов банка несут ответственность за результаты управления банковскими рисками. В связи с этим совет директоров и исполнительные органы банка должны организовать координацию управления всеми банковскими рисками.

Е. С. Васильев определил структуру корпоративного управления коммерческого банка как совокупность элементов, их характеристик и ключевых принципов взаимоотношений между ними. Часто под «структурами» корпоративного управления понимается два руководящих органа банка- совет директоров и правление(менеджмент). Но структура корпоративного управления - понятие более широкое. Основными структурными элементами в корпоративном управлении выступают [7]:

- общее собрание акционеров (участников) - главный орган управления, определяющий структуру управления коммерческим банком, утверждающий состав совета директоров (наблюдательного совета) и в случаях, предусмотренных уставом банка (т. е. в соответствии с решением собственников при утверждении устава), кандидатуру единоличного исполнительного органа и состав коллегиального исполнительного органа;

- совет директоров (наблюдательный орган) - орган общего стратегического управления коммерческим банком, уполномоченный определить направление развития кредитной организации, отслеживать результативность достижения стратегических целей и реализации тактических планов и осуществлять общий контроль за деятельностью банка;

\section{Baikal Research Journal}


- коллегиальный исполнительный орган (менеджмент, правление, дирекция, администрация) и единоличный исполнительный орган (председатель правления, директор, генеральный директор) осуществляют текущее руководство деятельностью кредитной организации, решают вопросы, связанные с эффективной оперативной работой коммерческого банка, на регулярной основе предпринимаются шаги, направленные на реализацию тактических планов;

- служба внутреннего контроля (внутренний аудит). Кредитная организация обязана организовывать внутренний контроль, обеспечивающий надлежащий уровень надежности, соответствующей характеру и масштабам проводимых операций;

- ревизионная комиссия является органом коммерческого банка, осуществляющим функции внутреннего контроля за финансово-хозяйственной деятельностью коммерческого банка, его подразделений и служб, филиалов и представительств.

Также структуру корпоративного управления могут дополнять различные производственные элементы в зависимости от конкретных условий функционирования банка.

Для получения полноценной структуры корпоративного управления коммерческим банком авторами предлагается методика, посредством которой реализуются последовательные шаги по определению параметров органов управления банка, их основных характеристик и предпочтительных форм взаимодействия как с внутренней, так и внешней средой коммерческого банка.

В алгоритме выделены следующие блоки [7]:

- определения общих характеристик организационной структуры управления банком;

- распределения полномочий между органами управления банка;

- параметризации периодичности и форм отчетности нижестоящих органов управления перед вышестоящими органами управления коммерческим банком;

- определения характера взаимоотношений с внешней средой коммерческого банка (учет интересов всех заинтересованных сторон, раскрытие информации и прозрачность).

М. Н. Аботина утверждает, что при создании условий надлежащего корпоративного управления в системе функционирования коммерческих банков можно выделить следующие основные направления [8]:

- делегирование полномочий, вопросов компетенции и подотчетности между органами управления (с учетом положений действующего законодательства), организация эффективной деятельности совета директоров (наблюдательного совета) и исполнительных органов;

- определение и утверждение стратегии развития деятельности кредитной организации и контроль за ее реализацией (включая построение эффективных систем планирования, управления банковскими рисками и внутреннего контроля);

- минимизация конфликтов интересов, которые возникают между участниками (акционерами), членами совета директоров (наблюдательного совета) и исполнительных органов, служащими, кредиторами, вкладчиками, иными клиентами и контрагентами;

- определение правил и процедур, обеспечивающих соблюдение принципов профессиональной этики и компетенции;

- определение порядка и контроль за раскрытием информации о кредитной организации.

Задача улучшения состояния корпоративного управления в коммерческом банке обусловлена растущей конкуренцией с западными и ведущими российскими банками, а также необходимостью увеличения стоимости банков (в том числе для эффективной их продажи более успешному конкуренту). Эти факторы в ближай-

\section{Baikal Research Journal}


шее время будут основными двигателями практического внедрения в банковском секторе принципов корпоративного управления, поэтому Банк России все больше внимания уделяет оценке состояния корпоративного управления. Динамику этого процесса отслеживают как его надзорные органы, независимые эксперты и контролеры (аудиторы), так и сами коммерческие банки (самооценка).

Банки должны использовать самые высокие стандарты в процедурах управления рисками, особенно при оценке риска их потенциальных инвестиций, включая корпоративное кредитование. Некоторые банки бывают вынуждены это сделать из-за давления регуляторов и правовых органов. Банки, которые выбирают модель лидера в сфере корпоративного управления, могут рассчитывать не только на получение большей прибыли в будущем, но и на значительный вклад в устойчивое развитие региона, в котором они осуществляют деятельность.

Введение и совершенствование корпоративного управления позволит оптимизировать совершенствование собственных и заемных средств для выполнения функции финансового посредничества, будет способствовать упрочнению деловой репутации коммерческого банка и увеличению доли заемных средств, которые предопределяют повышенную рискованность банковских пассивов, заметное расхождение между временными структурами пассивов и активов, а также критическую зависимость коммерческого банка от доверия множества вкладчиков [8].

В. Г. Герасимов и Ж. Г. Абусалимова определили риски корпоративного управления в коммерческих банках и сообщают, что риски корпоративного управления проявляются в вероятности отклонения действий от планируемых, что приводит к финансовым потерям [9, с. 170$]$.

Риски корпоративного управления возникают в ходе реализации отношений между акционерами и менеджерами, различными группами акционеров, имеющими неравные возможности для контроля за системой управления банком, между банком и иными участниками, заинтересованными в его деятельности (рис.).

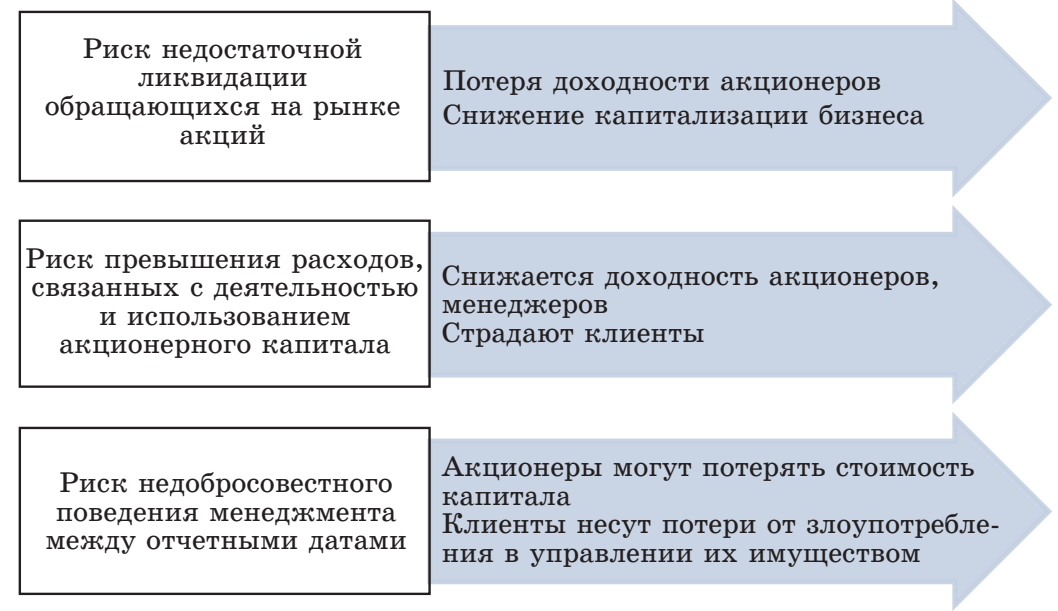

Основные риски корпоративного управления (Составлено по данным [9])

Исходя из имеющихся в литературе упоминаний, можно сделать вывод, что особенности корпоративного управления банков стали представлять определенный интерес во время и после азиатского кризиса 1997 г. [10]. С этого момента в соответствии с более общей тенденцией банки во всем мире стали публично подчеркивать, что хорошее корпоративное управление является жизненно важным

\section{Baikal Research Journal}

электронный научный журнал Байкальского государственного университета 
для компании, и даже начали принимать индивидуальные кодексы корпоративного управления.

Следуя тенденции, Базельский комитет по банковскому надзору опубликовал первое издание своего вышеупомянутого руководства «Совершенствование корпоративного управления в банковской сфере». Некоторые национальные органы банковского надзора даже опубликовали правила, детализирующие структуры и функции корпоративного управления, требуемые банками, в частности, Швейцарский орган по надзору за финансовым рынком (FINMA, ранее Швейцарский орган банковского надзора) и Banca d'Italia ${ }^{2}$.

Дальнейшее меняющееся отношение банков, надзорных органов и теоретиков к роли корпоративного управления в коммерческом банке в период финансовых кризисов можно условно разделить на два этапа:

1. Отсутствие значительного влияния корпоративного управления на вероятность банкротства банка, причины и последствия финансового кризиса.

После начала финансовых потрясений летом 2007 г. проблема корпоративного управления банков, за исключением вознаграждения руководства, в течение некоторого времени выходила из фокуса. В многочисленных докладах, документах и заявлениях, опубликованных в 2008 г., посвященных причинам и последствиям финансового кризиса, даже не упоминается о корпоративном управлении ${ }^{3}$. Это относится, в частности, к отчетам, подготовленным Рабочей группой Президента США по финансовым рынкам ${ }^{4}$. В то же время практика вознаграждения руководства банков вызвала большой интерес с самого начала кризиса. Даже без каких-либо убедительных доказательств, доступных до сих пор, сильно сконцентрированные, ориентированные на краткосрочную перспективу вознаграждения наряду с большой долей «жадности» со стороны банкиров рассматривались как одна из важнейших или даже самая важная причина финансовых потрясений. Как следствие, предложения по реформированию этой области вскоре изобиловали как на международном, так и на национальном уровне [1, с. 7-8].

2. Неэффективное корпоративное управление банков начинает восприниматься как одна из основных причин кризисов. В течение второго года финансового кризиса 2008 года вопрос о корпоративном управлении банков начал возрождаться с удвоенной силой, начиная с ОЭСР. Руководящая группа ОЭСР по корпоративному управлению, исходя из предпосылки о том, что проблемы корпоративного управления в банках принципиально не отличаются от проблем общих корпораций, впервые поручил провести исследование по выявлению фактов по четырем направлениям корпоративного управления (вознаграждение руководства, управление рисками, практики управления и осуществления прав акционеров) [11].

«Большая двадцатка» на своем лондонском саммите в апреле 2009 г. также признала важность этого вопроса, хотя и косвенным образом. Группа по финансовому надзору в ЕС, возглавляемая Жћаком де Ларозьером, прямо заявила в своем докладе, что корпоративное управление банками «является одним из наиболее важных провалов нынешнего кризиса». На уровне государств-членов $\mathrm{EC}$, в частности, выражаются очень похожие оценки в Великобритании. Ассоци-

\footnotetext{
${ }^{2}$ Banca d'Italia. Supervisory Provisions concerning banks' organization and corporate governance (Decree of March 4, 2008). URL: http://www.bancaditalia.it/vigilanza/banche/normativa/disposizioni/provv; see Banche, governo socie-tario e funzioni di vigilanza // Quaderni di Ricerca Giuridica: della Consulenza Legale. 2008. № 62. P. 8-38. URL: http://www.bancaditalia.it/pubblicazioni/quarigi/qrg62/qrg_62.

${ }^{3}$ Financial Stability Forum «Report of the Financial Stability Forum on Enhancing Market and Institutional Resilience», April 7, 2008. URL: http://www.financialstabilityboard.org/list/fsb_publications/ page_3.htm. 21 .

${ }^{\overline{4}}$ The President's Working Group on Financial Markets «Policy Statement on Financial Markets», March 2008. URL: http://www.ustreas.gov/press/releases/reports/pwgpolicystatemktturmoil_03122008.pdf.
}

\section{Baikal Research Journal}


ация сертифицированных бухгалтеров (ACCA) «считает, что кредитный кризис может ... быть рассмотрен, в значительной степени, как провал в корпоративном управлении». Неудивительно, что изменившееся восприятие взаимосвязи между кризисом и корпоративным управлением банков также отражено в многочисленных эмпирических и теоретических исследованиях [1, с. 9; 12].

Таким образом, по результатам обзора имеющихся научных подходов к вопросу о роли корпоративного управления в системе минимизации рисков коммерческого банка, можно сделать вывод, что на сегодняшний момент важность этого направления уже не вызывает сомнений ни в теоретических работах, ни в представлениях руководства, собственников и надзорных органах. А многочисленные исследования влияния корпоративного управления на способность организации преодолеть кризисные явления в экономике с наименьшими потерями подтверждают гипотезу о взаимосвязи грамотного корпоративного управления с экономической безопасностью субъекта.

\section{Список использованной литературы}

1. Müllbert P. O. Corporate governance of banks after the financial crisis - theory, evidence, reforms / P. O. Müllbert. - 2010. - 39 p. - (ECGI Working Paper Series in Law, № 151).

2. Corporate governance, regulation and supervision of banks / J. Devriese [et al.] // Financial Stability Review. - 2004. - Vol. 2, № 1. - P. 95-120.

3. Macey J. R. Corporate governance and commercial banking: A comparative examination of Germany, Japan, and the United States / J. R. Macey, G. P. Miller // Stanford Law Review. - 1995. - Vol. 48, № 1. - P. 73-112.

4. Shleifer A. A survey of corporate governance / A. Shleifer, R. W. Vishny // The Journal of Finance. - 1997. - Vol. 52, № 2. - P. 737-783.

5. Заварихин Н. М. Корпоративное управление в российских коммерческих банках / Н. М. Заварихин, М. Н. Останин // Финансовый менеджмент. - 2007. - № 3. - С. 3-7.

6. Федорова Е. А. Риск-менеджмент в процессе корпоративного управления деятельностью коммерческого банка / Е. А. Федорова, В. И. Белоцерковский // Известия Тульского государственного университета. Экономические и юридические науки. -2010 . № 1-2. - C. 192-201.

7. Васильев Е. С. Формирование структуры корпоративного управления коммерческим банком / Е. С. Васильев // Известия Тульского государственного университета. Экономические и юридические науки. - 2011. - № 1-1. - С. 245-254.

8. Аботина М. Н. Проблемы совершенствования корпоративного управления в коммерческих банках / М. Н. Аботина // Вестник Саратовского государственного социально-экономического университета. - 2008. - № 1. - С. 60-62.

9. Герасимов В. Г. Корпоративное управление и риск-менеджмент в коммерческом банке / В. Г. Герасимов, Ж. Л. Абусалимова // Вестник Белгородского университета кооперации, экономики и права. - 2013. - № 3. - С. 167-174.

10. Corporate governance in the Asian financial crisis / S. Johnson [et al.] // Journal of financial Economics. - 2000. - Vol. 58, № 1. - P. 141-186.

11. Kirkpatrick G. The corporate governance lessons from the financial crisis / G. Kirkpatrick // OECD Journal: Financial Market Trends. - 2009. - Vol. 2009, № 1. - P. 61-87.

12. Adams R. B. Governance and the financial crisis / R. B. Adams // International Review of Finance. - 2012. - Vol. 12, № 1. - P. 7-38.

\section{References}

1. Müllbert P. O. Corporate Governance of Banks after the Financial Crisis - Theory, Evidence, Reforms. ECGI Working Paper Series in Law, 2010, no. 151. 39 p.

2. Devriese J. [et al.]. Corporate governance, regulation and supervision of banks. Financial Stability Review, 2004, vol. 2, no. 1, pp. 95-120.

3. Macey J. R., Miller G. P. Corporate governance and commercial banking: A comparative examination of Germany, Japan, and the United States. Stanford Law Review, 1995, vol. 48, no. 1 , pp. $73-112$.

\section{Baikal Research Journal}


4. Shleifer A., Vishny R. W. A survey of corporate governance. The Journal of Finance, 1997, vol. 52, no. 2, pp. 737-783.

5. Zavarikhin N. M., Ostanin M. N. Corporate management in Russian commercial banks. Finansovyi menedzhment $=$ Financial Management, 2007, no. 3, pp. 3-7. (In Russian).

6. Fedorova E. A., Belotserkovsky V. I. Risk management in process of corporate management of commercial bank's activity. Izvestiya Tul'skogo gosudarstvennogo universiteta. Ekonomicheskie i yuridicheskie nauki = Bulletin of Tula State University. Economic and Legal Sciences, 2010, no. 1-2, pp. 192-201. (In Russian).

7. Vasilyev E. C. Formation of the structure of corporate governance of commercial banks. Izvestiya Tul'skogo gosudarstvennogo universiteta. Ekonomicheskie $i$ yuridicheskie nauki= Bulletin of Tula State University. Economic and Legal Sciences, 2011, no. 1-1, pp. 245-254. (In Russian).

8. Abotina M. N. Problems of improving cooperative management in commercial banks. Vestnik Saratovskogo gosudarstvennogo sotsial'no-ekonomicheskogo universiteta $=$ Bulletin of Saratov State Socio-Economic University, 2008, no. 1, pp. 60-62. (In Russian).

9. Gerasimov V. G., Abusalimov Zh. L. Corporate Management and Risk Management in Commercial Bank. Vestnik Belgorodskogo universiteta kooperatsii, ekonomiki $i$ prava $=$ Bulletin of Belgorod University of cooperation, Economics and law, 2013, no. 3, pp. 167-174. (In Russian).

10. Johnson S. [et al.]. Corporate governance in the Asian financial crisis. Journal of financial Economics, 2000, vol. 58, no. 1, pp. 141-186.

11. Kirkpatrick G. The corporate governance lessons from the financial crisis. OECD Journal: Financial Market Trends, 2009, vol. 2009, no. 1, pp. 61-87.

12. Adams R. B. Governance and the financial crisis. International Review of Finance, 2012, vol. 12, no. 1, pp. 7-38.

\section{Информация об авторах}

Головань Евгений Игоревич - аспирант, кафедра банковского дела и ценных бумаг, Байкальский государственный университет, 664003, г. Иркутск, ул. Ленина, 11, e-mail : superdjen@mail.ru.

Оношко Ольга Юрьевна - кандидат экономических наук, доцент, кафедра банковского дела и ценных бумаг, Байкальский государственный университет, 664003, г. Иркутск, ул. Ленина, 11, e-mail: olga_onoshko@mail.ru.

\section{Authors}

Yevgeny I. Golovan - PhD Student, Chair of Banking and Securities, Baikal State University, 11 Lenin St., 664003, Irkutsk, Russian Federation; e-mail: superdjen@mail.ru.

Olga Yu. Onoshko - PhD in Economics, Associate Professor, Chair of Banking and Securities, Baikal State University, 11 Lenin St., 664003, Irkutsk, Russian Federation; e-mail: olga_onoshko@mail.ru.

\section{Библиографическое описание статьи}

Головань Е. И. Роль эффективного корпоративного управления в системе минимизации рисков коммерческого банка / Е. И. Головань, О. Ю. Оношко // Baikal Research Journal. 2017. — T. 8, № 2. - DOI: 10.17150/2411-6262.2017.8(2).10.

\section{Reference to article}

Golovan Ye. I., Onoshko O. Yu. Role of effective corporate management in the commercial bank's system of risk minimization. Baikal Research Journal, 2017, vol. 8, no. 2. DOI: 10.17150/2411-6262.2017.8(2).10. (In Russian).

\section{Baikal Research Journal}

